\title{
Clinical significance of aggressive hepatectomy for colorectal liver metastasis, evaluated from the HGF/c-Met pathway
}

\author{
SATOSHI MATSUI, SHINJI OSADA, HIROYUKI TOMITA, SHUJI KOMORI, RYUTARO MORI, \\ YUICHI SANADA, TAKAO TAKAHASHI, KAZUYA YAMAGUCHI and KAZUHIRO YOSHIDA \\ Department of Surgical Oncology, Gifu University Graduate School of Medicine, \\ 1-1 Yanagido, Gifu 501-1194, Japan
}

Received January 8, 2010; Accepted May 3, 2010

DOI: 10.3892/ijo_00000677

\begin{abstract}
Liver metastasis is one of the most critical factors in deciding the prognosis of patients with colorectal cancer (CRC). Hepatectomy is the most curative treatment for liver metastasis of CRC. The high amount of hepatocyte growth factor (HGF) is produced to promote liver regeneration by hepatectomy. Theoretically, HGF produced after hepatectomy stimulates the progression of CRC cells with c-Met in residual liver. This study was aimed to evaluate the value of hepatectomy towards liver metastasis of $\mathrm{CRC}$ in relation to the $\mathrm{HGF} / \mathrm{c}-\mathrm{Met}$ pathway. Ninety-four patients with CRC (including 24 liver metastasis cases) were operated at Gifu University Hospital (2002-2004). For these cases, the expression of c-Met in the primary and liver metastatic sites was evaluated by immunohistochemistry and Western blot. Experiments were also conducted on CT26 murine CRC cell line and a mouse liver metastasis model. In clinical study, the c-Met expression in liver metastatic sites was lower than in the primary sites in $87 \%$ of 24 cases. In basic study, the expression of c-Met protein in the liver tumor was significantly lower than in culture cells according to Western blot $(\mathrm{p}=0.033)$. The growth of residual liver tumors was not significantly different between $30 \%$ hepatectomy group and no operation group. The over-expression of c-Met was closely associated with CRC liver metastases. On the other hand, in liver metastatic lesions, the c-Met expression was reduced in comparison to primary lesions. Therefore, even if serum HGF levels increased due to liver resection during the regeneration period, residual liver metastases of CRC was not promoted in its progression. Aggressive hepatectomy would still be acceptable and favorable as a curative therapy.
\end{abstract}

Correspondence to: Dr Shinji Osada, Department of Surgical Oncology, Gifu University Graduate School of Medicine, 1-1 Yanagido, Gifu 501-1194, Japan

E-mail: sting@gifu-u.ac.jp

Key words: c-Met, hepatocyte growth factor, liver metastasis, colorectal cancer, signal transduction

\section{Introduction}

Colorectal cancer $(\mathrm{CRC})$ is the third most common cancer worldwide followed by lung and breast cancer, accounting for more than one million new cases and 500,000 deaths per year (1). At some point in the natural course of CRC, up to $50 \%$ of patients will develop metastasis to the liver (2). There is no therapy available that will allow survival in these cases over 12 months $(3,4)$. Therefore, the arguments about treatments for liver metastasis are quite important for deciding patient prognosis. Among these concepts, recent surgical progress has led to the aggressive resection of visible liver tumors becoming the gold standard treatment (2). This surgical procedure brings about favorable clinical outcomes, but the propriety of these treatments should be demonstrated by a molecular study for expanding therapeutic benefit.

Hepatocyte growth factor/scatter factor (HGF/SF) and its receptor, c-Met, which was initially discovered as a protooncogene $(5,6)$, are well-known to be associated with liver regeneration (6) and the development of normal organs, such as placenta, muscle and central nervous system (7). The observation of c-Met over-expression or activation has focused on CRC progression with the expression level of primary cancer ranging from 2 to 50 times higher than normal mucosa (8). In addition, the c-Met pathway has been indicated as playing a critical role in the step from carcinogenesis to the advanced stage of CRC (9). On the other hand, after hepatectomy as a treatment of metastatic liver tumors, activation of the signaling pathway from c-Met related HGF represents an important factor in the progress of liver regeneration (10). These factors taken together raise concern that increased levels of serum HGF following hepatectomy might prompt the growth of colorectal cancer cells over-expressing c-Met. To determine the value of surgical resection for CRC metastatic tumors of the liver, the biological responses around hepatectomy should be considered with an understanding for the particular features of CRC. The development of surgical procedures was estimated from the viewpoint of c-Met expression in CRC progression in the present study.

\section{Patients and methods}

Patients. Among the patients who underwent surgical treatment for CRC at the Department of Surgical Oncology, 
Gifu University Hospital between January 2002 to December 2004, 24 cases had liver metastasis. Because of cancer infiltration into the muscular layer in these cases of liver metastasis, another 70 cases of muscular layer invasion without liver metastasis were used to compare for c-Met expression or other clinicopathological features. The experiments were performed in accord with the ethical standards of the Helsinki Declaration of 1975.

Cell lines and culture conditions. CT26 cells, a murine colorectal carcinoma cell line, were obtained from the American Type Culture Collection (ATCC, Manassas, VA, USA). Cells were maintained in RPMI-1640 in sodium bicarbonate and L-glutamate (Sigma, St. Louis, MO, USA) supplemented with $10 \%$ heat-inactivated fetal bovine serum (FBS), $1 \mathrm{mM}$ of HEPES buffer, $1 \mathrm{mM}$ of sodium pyruvate solution and $1 \%$ of an antibiotics/mycotics solution (Sigma). Cells were cultured in the $\mathrm{CO}_{2}$ incubator at $37^{\circ} \mathrm{C}$ in a humidified atmosphere at $5 \% \mathrm{CO}_{2}$ and $95 \%$ air. Cells were passaged two times weekly.

Animals and in vivo experiments. Male BALB/c mice, 5 weeks old, were purchased from SRL (Hamamatsu, Japan) and kept in the local central animal facility. The mice were housed under standard conditions and had free access to water and food. Animal procedures were performed in accordance with approved protocols and following recommendations for proper care and use of laboratory animals.

A liver metastatic model of CRC was made by injection of $1.0 \times 10^{6}$ of CT26 cells into spleen of BALB/c mouse, as described previously (11). At 7, 14, 21 and 28 days after injection, murine spleen and liver were removed and evaluated by Western blot analysis, immunohistochemical study and real-time RT-PCR. The resected specimen was preserved so as to prevent contamination from genomic DNA. Specimens were stored as is at $-80^{\circ} \mathrm{C}$ or preserved at $-20^{\circ} \mathrm{C}$ in RNAlater solution (Ambion, Austin, TX, USA) for RNA examination.

Blood collection from mice was performed by submandibular bleeding methods. The bleeding targets the retroorbital and submandibular veins draining the face of the mouse at the point that they join at the origin of the jugular vein. The serum HGF level was evaluated by ELISA method (Tokushu Meneki, Tokyo, Japan). A sample (50 $\mu \mathrm{l})$ and the same volume of diluted solution were incubated with antiHGF mouse monoclonal antibody for $20 \mathrm{~h}$. After reaction with rabbit polyclonal anti-HGF antibody for $2 \mathrm{~h}$, peroxidase labeled anti-rabbit immunoglobulin antibody was added for another $2 \mathrm{~h}$. The reaction was stopped by a $0.1 \mathrm{~N}$ sulfuric acid solution and the absorbance of each well was measured with a microplate reader (measuring wavelength $492 \mathrm{~nm}$ and the reference wavelength $620 \mathrm{~nm}$ ).

Hepatectomy was performed to correlate serum HGF levels with cancer proliferation or liver regeneration. Thirty per cent hepatectomy was performed by left lateral robectomy and $70 \%$ hepatectomy was performed by left lateral and median robectomy. Tumor volume was calculated according to the formula of $1 / 2 \times$ (long diameter) $\mathrm{x}$ (short diameter) ${ }^{2}$, and was well correlation with the water displacement method $(\mathrm{r}=0.98)(12,13)$.
Cell proliferation assay. To examine the proliferation of CT26, cells were cultured in serum-free medium, and with several factors added subsequently. Proliferation was evaluated by the 3-(4,5-dimethylthiazol)-2, 5-dephenyl tetrazolium bromide (MTT) test as described previously (14). To evaluate the proliferative effect of HGF, VEGF and EGF (R\&D Systems, Minneapolis, MN, USA), growth factors were used. Cells $\left(5 \times 10^{3}\right)$ were seeded in each well of a 24-well plate, and maintained in the usual culture medium overnight. The medium was changed for serum-free RPMI-1640 medium, and after $24 \mathrm{~h}$ incubation, growth stimulation by growth factors was started (20 or $40 \mathrm{ng} / \mathrm{ml}$ of HGF or EGF, or 10 or $20 \mathrm{ng} / \mathrm{ml}$ of VEGF were added to each well at day 0 and day 4). All media were removed and replaced with media containing $0.5 \mathrm{mg} / \mathrm{ml} \mathrm{MTT} \mathrm{(Sigma)} \mathrm{followed} \mathrm{by} 2 \mathrm{~h}$ incubation. Quantitation of solubilized formazan was performed by obtaining absorption readings at $550 \mathrm{~nm}$ wavelength on a microplate reader.

Immunohistochemistry. Specimens were fixed in $10 \%$ formalin and paraffin-embedded by conventional techniques. Freshly cut $5-\mu \mathrm{m}$ sections were deparaffinized in xylene, and the slides were bathed in $0.01 \mathrm{M}$ sodium citrate and heated in a microwave oven for $12 \mathrm{~min}$. The sections were incubated with polyclonal rabbit monoclonal anti-human c-Met antibody (1:200, Santa Cruz Biotechnology, Santa Cruz, CA) or goat monoclonal anti-mouse c-Met antibody (1:50, R\&D Systems) and kept at $4^{\circ} \mathrm{C}$ overnight. The slides were subsequently treated with appropriate secondary antibodies conjugated to biotin, then developed utilizing avidin-conjugated horseradish peroxidase (HRP) with diaminobenzamidine (DAB) as substrate and counterstained with hematoxylin. For the secondary developing reagents, Vectastain ABC kit (Vector Laboratories, Burlingame, CA, USA) was used. c-Met-stained cells exhibited a combined membranous and cytoplasmic pattern. These experimental steps followed previously reported methods $(15,16)$. The immunohistochemistry results for c-Met were arbitrarily classified into four scores dependent on the intensity of immunoreactivity (9): negative immunostaining, 0 ; very weak immunostaining, +1 ; medium positive immunostaining, +2 ; and strongly positive immunostaining, +3 . A total of 94 primary tumors were classified into two groups; 0 or +1 was low grade and +2 or +3 was high grade (Fig. 1). No specific staining was observed in the negative control slides prepared without primary antibody.

Western blot analysis. Surgically removed specimens were frozen in liquid nitrogen as soon as possible after procurement, as described previously (17). Both tumor and normal surrounding liver, or non-tumor tissue, were obtained from the same individual. Non-tumor tissue was removed from adjacent non-neoplastic liver at least $1 \mathrm{~cm}$ in clinical specimen and $5 \mathrm{~mm}$ in mouse specimens beyond the margin of the tumor. The specimens were lysed in $1 \mathrm{ml}$ of lysis buffer (150 mM NaCl, $50 \mathrm{mM}$ Tris- $\mathrm{HCl}, \mathrm{pH}$ 8.0, 0.1\% SDS, $1 \%$ Triton $\mathrm{X}-100,1 \mathrm{mM}$ orthovanadate, $1 \mathrm{mM}$ phenylmethylsulfonyl fluoride, $10 \mathrm{ng} / \mathrm{ml}$ leupeptin, $10 \mathrm{ng} / \mathrm{ml}$ aprotinin). Insoluble material was removed by microcentrifugation at $13,000 \mathrm{rpm}$ for $15 \mathrm{~min}$ at $4^{\circ} \mathrm{C}$. Cell lysates 
(40 $\mu \mathrm{g}$ of protein/lane) were subjected to electrophoresis (PAGE) using 10\% SDS-polyacrylamide gels (Bio-Rad, Hercules, CA). The proteins were transferred to a polyvinylidene difluoride membrane (Millipore, Billerica, MA, USA). After blocking the membrane with Trisbufferd saline with Tween-20 (10 mM Tris-HCl, pH 8.0, $150 \mathrm{mM} \mathrm{NaCl}, 0.05 \%$ Tween-20) containing 5\% skim milk or $1 \%$ bovine serum albumin, the membrane was incubated with anti-human c-Met antibody (Santa Cruz Biotechnology), anti-mouse c-Met monoclonal antibody (R\&D Systems), phospho p44/42 MAPkinase (Erk1/2) antibody (Cell Signaling Technology, Denver, MA, USA), mouse monoclonal anti-cyclin B1 antibody (Santa Cruz Biotechnology), and mouse monoclonal anti-cyclin D1 antibody (Calbiochem, San Diego, CA, USA). The membrane was incubated with appropriate secondary antibody; anti-IgG antibody coupled to horseradish peroxidase. Detection was performed with enhanced chemiluminescence reagents (Perkin-Elmer, Waltham, MA, USA). The detected band was analyzed by ImageJ computer software, as described previously (18). Each value was obtained from the comparison with the level of rabbit polyclonal anti $ß$-actin (Abcam, Cambridge, UK), and the mean values were calculated from three repeated measures. The above-mentioned methods were applied to the basic study of CT26 and also to the mouse liver metastatic model.

Immunoprecipitation. For detection of the phosphorylation of c-Met in CT26, immunoprecipitation was preformed. Cells $\left(1 \times 10^{5}\right)$ were seeded on a $10-\mathrm{cm}$ dish, and stimulated with $40 \mathrm{ng} / \mathrm{ml}$ of HGF with the same method as the cell proliferation assay. All cells on the $10-\mathrm{cm}$ dish were dissolved by $500 \mu 1$ of RIPA buffer. For immunoprecipitation, mouse c-Met antibody (R\&D Systems) at the concentration of $1 / 100$ was added to the solution for $2 \mathrm{~h}$ and were combined with $100 \mu \mathrm{l}$ of protein $\mathrm{G}$ agarose beads (GE Healthcare, Buckinghamshire, UK) for $2 \mathrm{~h}$. Washing and centrifuging were repeated three times, and then the detection of phospho-c-Met protein was evaluated by Western blot with phospho-tyrosine antibody (Cell Signaling Technology).

Real-time reverse transcription-polymerase chain reaction (real-time RT-PCR). RNA of resected tissue or cultured cell was isolated using a Qiagen RNeasy mini kit (Qiagen, Germantown, MD, USA) as described previously (19). cDNA was synthesized from $5 \mu \mathrm{g}$ total RNA using oligo-dT primers and Superscript III reverse Transcriptase (Invitrogen, San Diego, CA, USA). Quantitative PCR analysis was performed using a Thermal Cycler Dice real-time system (Takara Bio. Inc., Japan) with SYBR-Green staining of DNA double-strands. The amplification profile consisted of $50^{\circ} \mathrm{C}$ for $2 \mathrm{~min}, 95^{\circ} \mathrm{C}$ for $10 \mathrm{~min}, 40$ cycles of denaturing at $95^{\circ} \mathrm{C}$ for $15 \mathrm{sec}$, and annealing at $60^{\circ} \mathrm{C}$ for $1 \mathrm{~min}$. The following primer pairs were used: mouse c-Met (sense: 5-GAGACC CAGTTCAACGACAGCA-3, antisense: 5-CTGTAACAAC AGCCAAGTTCAACGA-3), and mouse GAPDH (sense: 5TGTGTCCGTCGTGGATCTGA-3, anti-sense: 5-TTGCTG TTGAAGTCGCAGGAG-3). PCR analysis was performed using SYBR-Green master mix, according to the manufacturer's recommendations (Takara Bio Inc.). Each mRNA
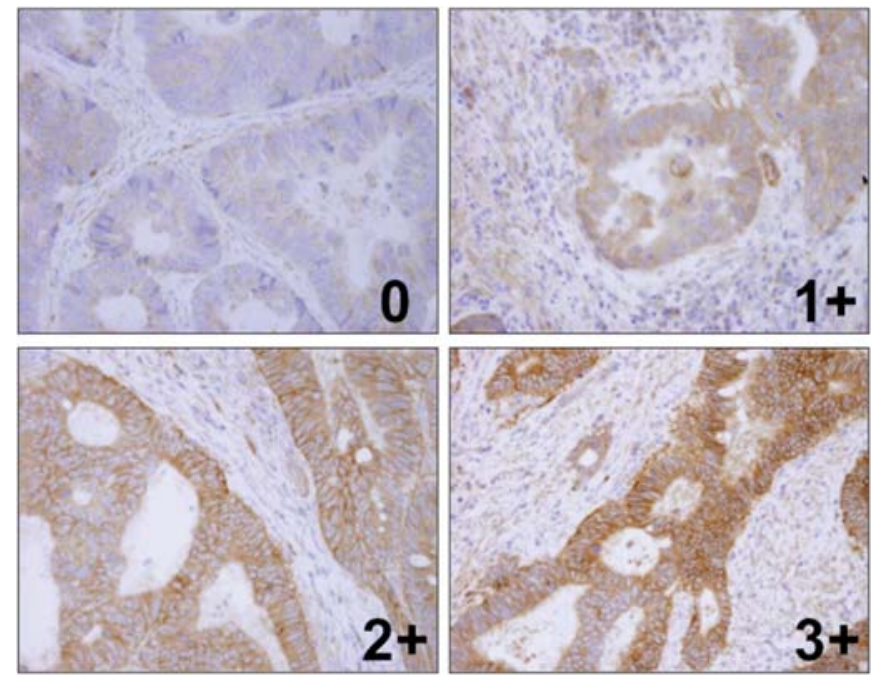

Figure 1. The expression of c-Met in primary lesions of colorectal carcinoma by immunohistochemistry $(n=94)$ : the immunohistochemistry results for c-Met were arbitrarily classified into four scores dependent on the intensity of immunoreactivity: negative immunostaining, 0; weak immunostaining, +1 ; medium positive immunostaining, +2 ; and strongly positive immunostaining, +3 . In addition, these four groups were classified into two groups; 0 or +1 was the low-grade group, +2 or +3 was the high-grade group.

value was normalized to that of the housekeeping mRNA, glyceraldehyde-3-phosphate dehydrogenase (GAPDH), using the standard curve method. Each experiment was done in either duplicate or triplicate, and then, the average was calculated.

Statistical analyses. All numerical data are presented as means \pm S.D. The data were examined using Student's t-test, Chi-square test and ANOVA or Kruskal-Wallis test (with appropriate post-hoc analysis for multiple comparisons) to determine the statistical significances. $\mathrm{p}<0.05$ were regarded as statistically significant.

\section{Results}

Clinical features, and their correlation with immunohistochemical findings. Clinicopathological characteristics are shown for statistical factors in Table I. Significant differences were not found for the other basic features (sex or age), depth of primary cancer invasion, location and size of tumor and pathological findings. Among the cases of liver metastasis, synchronous metastasis was detected in 15 cases, and metachronous metastasis was detected in 9 cases (median metachronous metastastatic time was 9 months; range was 3-18). In the group with a high expression of c-Met, the metastasis to lymph nodes and liver were significantly higher, at 58 and $87 \%$, respectively, despite the fact that there was no correlation for the other factors. In the CRC cases with liver metastasis, and in both synchronous and metachronous forms $(n=24)$, a high-grade immuno-activity of cMet in primary tumors was detected in 22 cases (91\%), but almost all these cases changed to low-grade activity in liver metastasis sites, except in 1 case (4\%) (Table II). Western 
Table I. The relationship between clinicopathological features and c-Met expression of patients with and without liver metastasis.

\begin{tabular}{lcc}
\hline $\begin{array}{l}\text { Patient characteristics } \\
(\mathrm{n}=94)\end{array}$ & $\begin{array}{c}\text { High expression } \\
(\mathrm{n}=62)\end{array}$ & $\begin{array}{c}\text { Low expression } \\
(\mathrm{n}=32)\end{array}$ \\
\hline $\begin{array}{l}\text { Venous invasion } \\
\mathrm{v}(-)\end{array}$ & $28(45)$ & $13(41)$ \\
$\mathrm{v}(+)$ & $34(55)$ & $19(59)$ \\
Lymph node metastasis & & $31(97)$ \\
$\mathrm{n}=0$ & $26(42)$ & $1(3)$ \\
$\mathrm{n}=1-3$ & $36(58)$ & \\
Liver metastasis & & $29(41)$ \\
No liver metastasis & $41(59)$ & $3(13)$ \\
Liver metastasis & $21(87)$ & 0.000 \\
\hline
\end{tabular}

The relationship between clinicopathological features and c-Met expression of patients with and without liver metastasis. Ninety-four clinical cases were separated into two groups followed by c-Met expression status, as shown in Fig. 1. CRC patients with liver metastasis (synchronous and metachronous) had significant lymph node metastasis at the time of presenting with primary CRC, compared to patients without liver metastasis $(\mathrm{p}<0.0001)$. The high-grade group was detected more frequently than the low-grade group among the liver metastasis group $(87 \%, \mathrm{p}=0.0316)$. Concerning other parameters, there was no significant difference between the two groups.

Table II. The relation between the primary site and liver metastatic site of c-Met status.

\begin{tabular}{|c|c|c|c|c|c|}
\hline & & \multicolumn{4}{|c|}{ c-Met status in primary/liver metastatic site } \\
\hline \multicolumn{2}{|c|}{ The pattern of liver metastasis } & High/high & Low/low & Low/high & High/low \\
\hline Synchronous & $\mathrm{n}=15$ & $1(4 \%)$ & $2(8 \%)$ & $0(0 \%)$ & $12(84 \%)$ \\
\hline Metachronous & $\mathrm{n}=9$ & $0(0 \%)$ & $0(0 \%)$ & $0(0 \%)$ & $9(100 \%)$ \\
\hline Total & $\mathrm{n}=24$ & $1(4 \%)$ & $2(8 \%)$ & $0(0 \%)$ & $21(87 \%)$ \\
\hline
\end{tabular}

The relation between the primary site and liver metastatic site of c-Met status was estimated for 24 cases with liver metastasis of CRC (synchronous metastasis case: 15; metachronous cases: 9). Both synchronous and metachronous pattern had the same tendency: the primary site was high in c-Met expression. On the other hand, the corresponding metastatic site was negative or had low expression (84 and 100\%). This phenomenon was detected in 21 of 24 total CRC patients with liver metastasis (87\%).

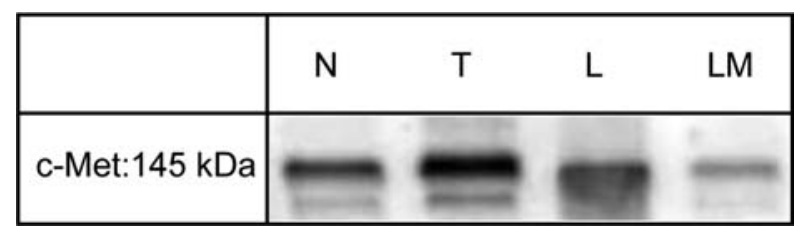

Figure 2. Western blot results of c-Met in five selected clinical cases with CRC liver metastasis $(n=5)$. In almost all cases, the expression of c-Met was strong in the primary tumor. On the other hand, the expression was reduced in the corresponding liver metastatic site. ( $\mathrm{N}$, normal colorectal mucosa; $\mathrm{T}$, CRC; L, normal liver tissue; LM, liver metastasis).

blot analysis of a small number of selected cases $(n=5)$ also indicated similar results to the immunohisto-chemical study (Fig. 2). Additionally, in these hepatectomy cases, the serum level of $\mathrm{HGF}$, at $0.35 \pm 0.02 \mathrm{ng} / \mathrm{ml}$ initially, increased significantly $(\mathrm{p}<0.0001)$ to $0.99 \pm 0.09 \mathrm{ng} / \mathrm{ml}$ post-operatively.

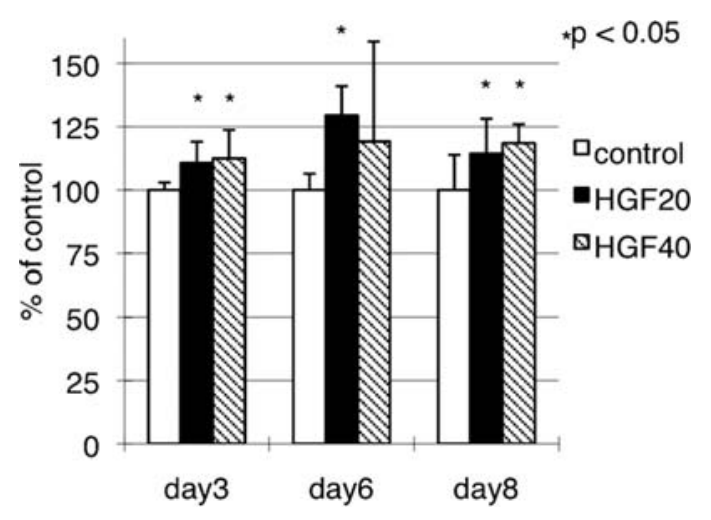

Figure 3. The proliferation of CT26 after being stimulated with HGF was evaluated. Cells $\left(5 \times 10^{3}\right)$ of CT26 were seeded in each well of a 24 -well plate. After $24 \mathrm{~h}$ of serum starvation, $20 \mathrm{or} 40 \mathrm{ng} / \mathrm{ml}$ of were added to each well at day 0 and day 4. At days 3,6 and 8, cell proliferation was evaluated by the MTT assay. CT26 increased significantly in cases of 20 and $40 \mathrm{ng} / \mathrm{ml}$ of HGF, when compared with the control group. 


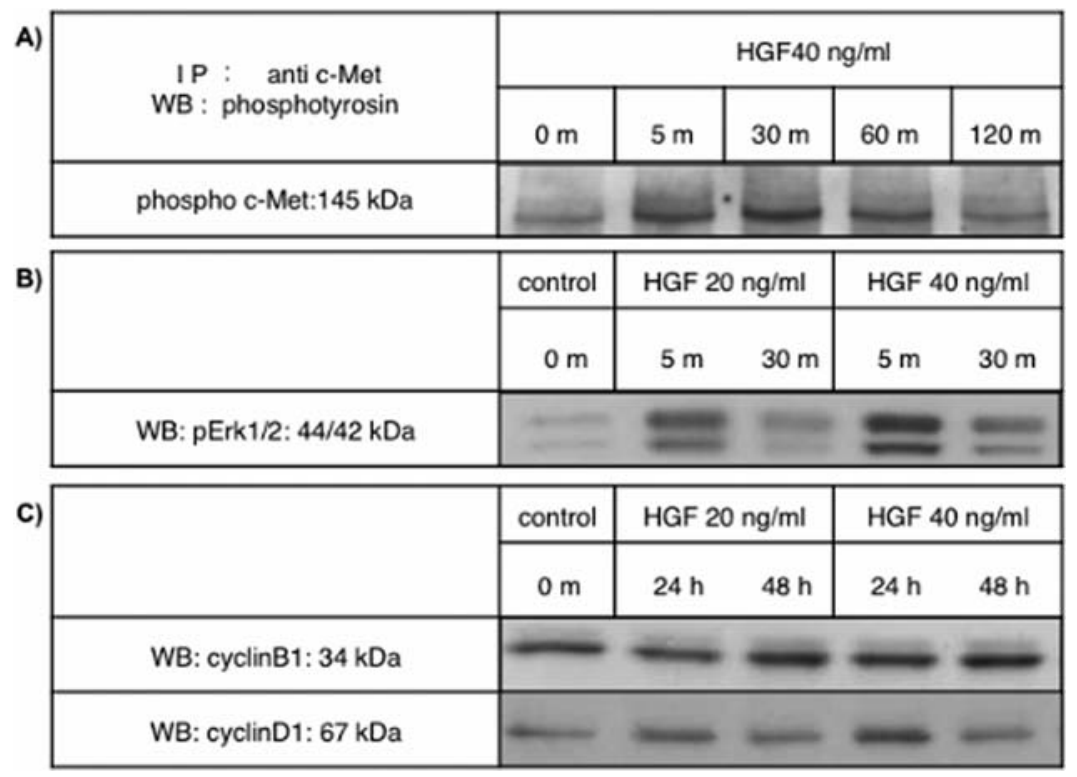

Figure 4. The phosphorylation of c-Met due to HGF and the expression of phospho-Erk, cyclin B1 and D1 in CT26 due to HGF was evaluated by Western blot analysis. (A) c-Met was activated by HGF throughout phosphorylation in CT26 cells with the peak 30 min later. (B) After 5 min of HGF stimulation, the peak of phospho-Erk activation was detected. Phospho-Erk was activated by HGF in a dose-dependent manner. (C) After 24-48 h of HGF stimulation, the peak of cyclin B1/D1 production was detected.

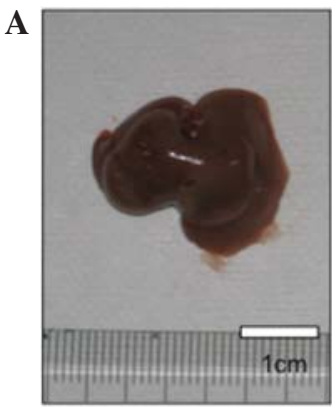

day 0

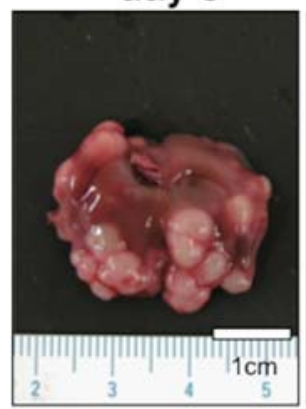

day 21

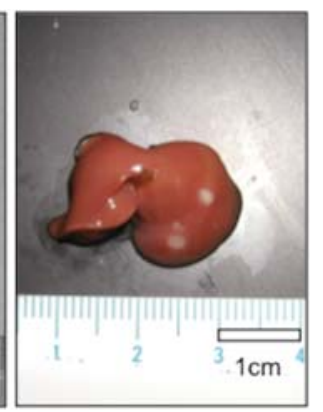

day 14

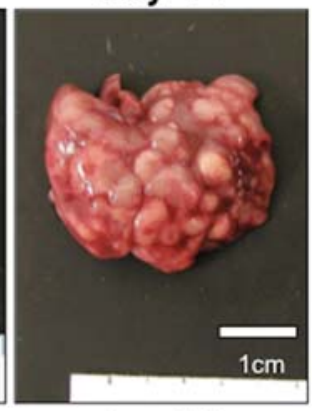

day 28
B

\begin{tabular}{|c|c|c|c|c|c|c|c|}
\hline & \multirow[b]{2}{*}{ culture cell } & \multicolumn{2}{|c|}{ day 14} & \multicolumn{2}{|c|}{ day 21} & \multicolumn{2}{|c|}{ day 28} \\
\hline & & LT & ST & LT & ST & LT & ST \\
\hline \multicolumn{8}{|l|}{ c-Met:145 kDa } \\
\hline \multicolumn{8}{|l|}{$\beta$-Actin:42 kDa } \\
\hline c-Met / $\beta$-Actin & 1.00 & 0.89 & 0.18 & 0.36 & 0.21 & 0.37 & 0.20 \\
\hline
\end{tabular}

Figure 5. The c-Met expression on day 14, 21 and 28 of culture cells (cell), spleen tumor (ST) and corresponding liver metastatic tumor (LT) was evaluated by Western blot. (A) Liver metastasis was not detected macroscopically on day 7, but was able to be detected macroscopically; $1 \mathrm{~mm}(0.1-5.0 \mathrm{~mm})$ on day 14; for $1 \mathrm{~mm}(0.1-12.0 \mathrm{~mm})$ on day 21 and $2 \mathrm{~mm}(0.1-6.0 \mathrm{~mm})$ on day 28 (each data presents the median and the range of diameter.) (B) The c-Met expression in liver metastatic tumors on day $14(\mathrm{n}=7)$ was significantly reduced compared with culture cells. The average immunoreactivity of liver tumors against culture cells was reduced by a factor of $0.76 \pm 0.11$ $(p=0.033)$ and that of spleen tumors by a factor of $0.44 \pm 0.30(p=0.001)$. The $\mathrm{c}$-Met expression in liver metastatic sites was reduced in a time-dependent manner.

Growth factor expression in vitro and in vivo. Cells were stimulated with growth factors HGF, EGF and VEGF. The cell proliferation was promoted significantly by HGF in a dose-dependent manner (Fig. 3), but the other growth factors showed no significant differences when they were combined (data not shown). According to Western blot analyses, c-Met was activated by addition of HGF, and its peak was detected at $30 \mathrm{~min}$ after a 5-min start with phosphorylation maintained over 120 min (Fig. 4A). ERK phosphorylation was found to peak 5 min after HGF addition (Fig. 4B), but phosphorylation was not detected after addition of either VEGF or EGF (data not shown). Additionally, the production of cyclin B1 and cyclin D1 increased from 12 to $48 \mathrm{~h}$ after HGF stimulation (Fig. 4C) but no stimulation of these factors was observed by VEGF or EGF.

The size of liver metastatic tumors was detected macroscopically, $1 \mathrm{~mm}(0.1-5.0 \mathrm{~mm})$ on day $14,1 \mathrm{~mm}(0.1-12.0 \mathrm{~mm})$ on day 21 , and approximately $2 \mathrm{~mm}$ (0.1-6.0 $\mathrm{mm}$ ) on day 28 (the data show the median and the range of diameter) (Fig. 5A). The expression of c-Met on day 14 decreased from 

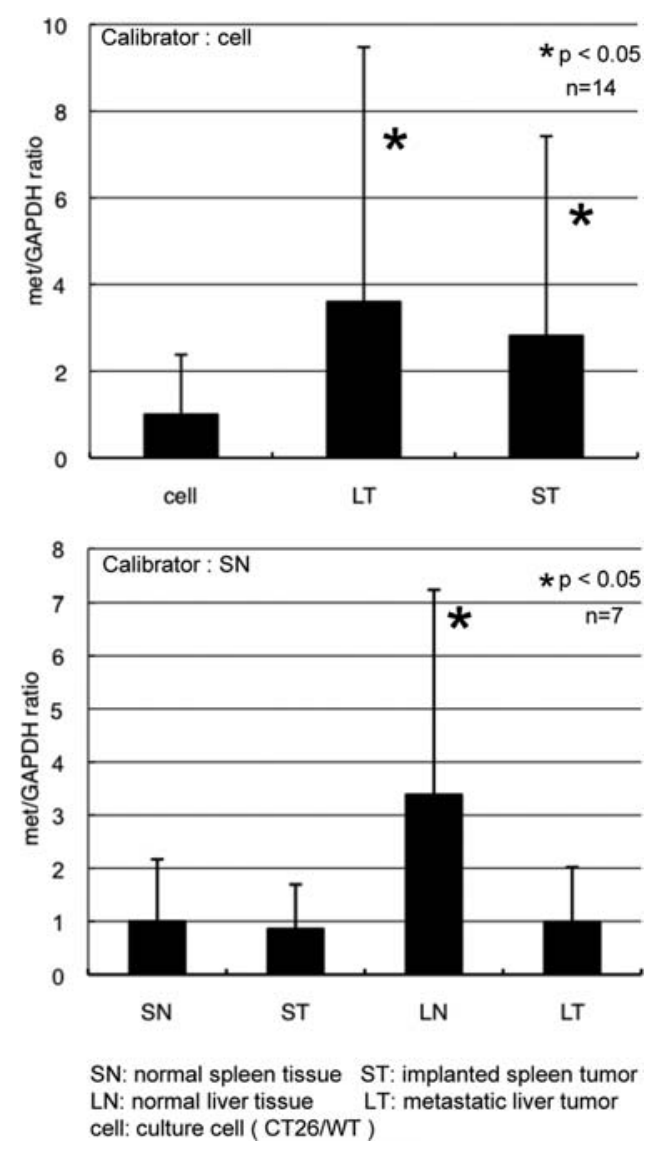

Figure 6. Relative quantification of c-Met mRNA was performed by realtime RT-PCR. The c-Met mRNA level in murine spleen tumors (ST) or murine liver metastatic tumors (LT) were significantly higher (2.82- and 3.60 -fold, $\mathrm{p}<0.05$ ) than that of culture cells (cell) in the case where the calibrator was cell. The c-Met mRNA level of normal murine liver tissue $(\mathrm{LN})$ was significantly higher $(3.39$-fold, $\mathrm{p}<0.05)$ than others in the case where the calibrator was normal murine spleen tissue (SN). Except in the cases above, there is no significant difference between the other cases.

cultured condition to metastasis (Fig. 5B), and the averages of c-Met/ $/$-actin were calculated as $0.44 \pm 0.30$ for spleen tumors $(\mathrm{p}=0.001)$ and $0.76 \pm 0.11$ for liver tumors $(\mathrm{p}=0.033)$. The c-Met mRNA level of spleen or liver tumors was significantly higher (2.82- or 3.60-fold, respectively) compared with cultured cells, but its level in normal liver tissue was higher (3.39-fold), than in the tumors (Fig. 6).

The effect of hepatectomy and c-Met expression. The serum HGF level was elevated by the $30 \%$ hepatectomy (lateral segmentectomy) and was 1.35 times higher than the shamoperated group at $12 \mathrm{~h}(\mathrm{p}<0.05)$ and returned to nonoperative (sham) levels by $48 \mathrm{~h}$ after staying high for $24 \mathrm{~h}$ (Fig. 7). In contrast, the elevation was not noted after the $70 \%$ hepatectomy [it was thought that an excessive liver removal was the caused of the low survival rate (3/10) and low serum HGF]. Then, in both the sham and the $30 \%$ hepatectomy $(30 \% \mathrm{H})$ groups, tumor progression was evaluated by measuring the size. The mean-detected tumor number of sham and remnant liver of $30 \% \mathrm{H}$ except for lateral segments were $10.0(\mathrm{n}=8)$ and $6.7(\mathrm{n}=6)$ on day 14 , and $16.6(n=11)$ and $15.4(n=7)$ on day 21 . Total tumor volumes of whole liver without lateral segments of sham

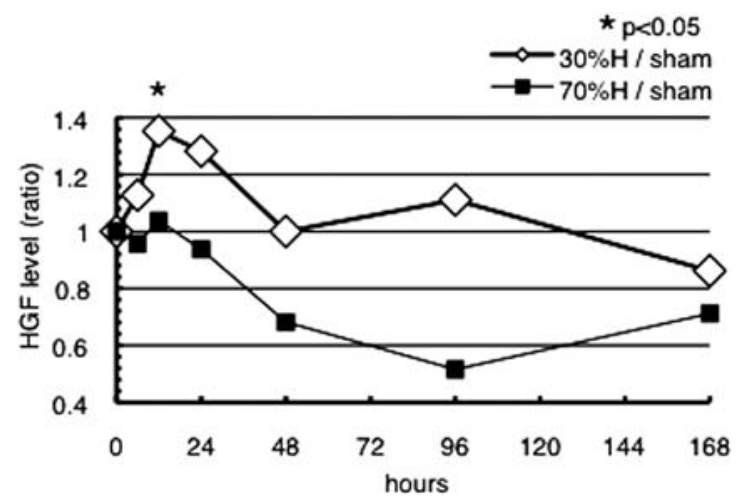

Figure 7. The serum HGF level of pre- or post-hepatectomy was evaluated by ELISA. The ratio (\%) that is the actual measurement of serum HGF on hepatectomy group to sham operation group was measured. The serum HGF level was elevated in the $30 \%$ hepatectomy group $(30 \% \mathrm{H}, \mathrm{n}=5)$ and was higher than sham group $(\mathrm{n}=5)$. The peak was at $12 \mathrm{~h}$ after hepatectomy and 1.35 times higher than the sham group $(\mathrm{p}<0.05)$. In the $70 \%$ hepatectomy group $(70 \% \mathrm{H}, \mathrm{n}=3)$, HGF was not elevated.

and remnant of the $30 \% \mathrm{H}$ were respectively $19.0 \pm 20.2$ and $5.3 \pm 5.8 \mathrm{~mm}^{3}$ on day 14 , and $633 \pm 171$ and $211 \pm 271 \mathrm{~mm}^{3}$ on day 21 . The mean volume of each tumor in sham and $30 \% \mathrm{H}$ was calculated as $5.8 \pm 3.0$ and $2.9 \pm 1.2 \mathrm{~mm}^{3}$ on day 14 , and $115.1 \pm 14.8$ and $60.7 \pm 15 \mathrm{~mm}^{3}$ on day 21 . There was no significant difference between sham and $30 \% \mathrm{H}$ in tumor number and volume after hepatectomy.

To demonstrate the transition of c-Met expression, immunohistochemistry was performed (Fig. 8). In the center of main tumor c-Met expression was clearly reduced, despite it remaining high in the invasive peripheral area of the main tumor. In addition, there was a difference in intraluminal lesions between still remaining growing space site and filling up occupied area, namely increasing and decreasing, respectively. In all removed tumors of the same mouse at 28 days, which showed range of sizes and weights, the level of c-Met expression evaluated by Western blot analysis was found to have a significant inverse correlation to tumor weight (Fig. 9).

\section{Discussion}

Liver metastasis represents one of the most critical issues that will decide the prognosis of CRC patients. Now, a variety of therapeutic approaches have been attempted for this problematic disease (20), with recent reports showing the benefit of surgical resection (21). Although the resectability rate is still unsatisfactory at only $20-30 \%(22,23)$, the operation itself is performed with a low mortality rate and around one-third of patients who have undergone hepatectomy will survive for 5 years or more (21-23). Therefore, aggressive concept to expand operative indication might be necessary for the future in the surgical field. To evaluate the surgical resection of CRC liver metastasis tumors, the biological responses due to the operation and also the characteristic markers of CRC should be monitored. Among these biological factors, it is important to note that over-expression of $\mathrm{c}$-Met mRNA and protein is associated with the progress of cancer towards distant metastasis $(8,9,24,25)$. In the present 
(A)
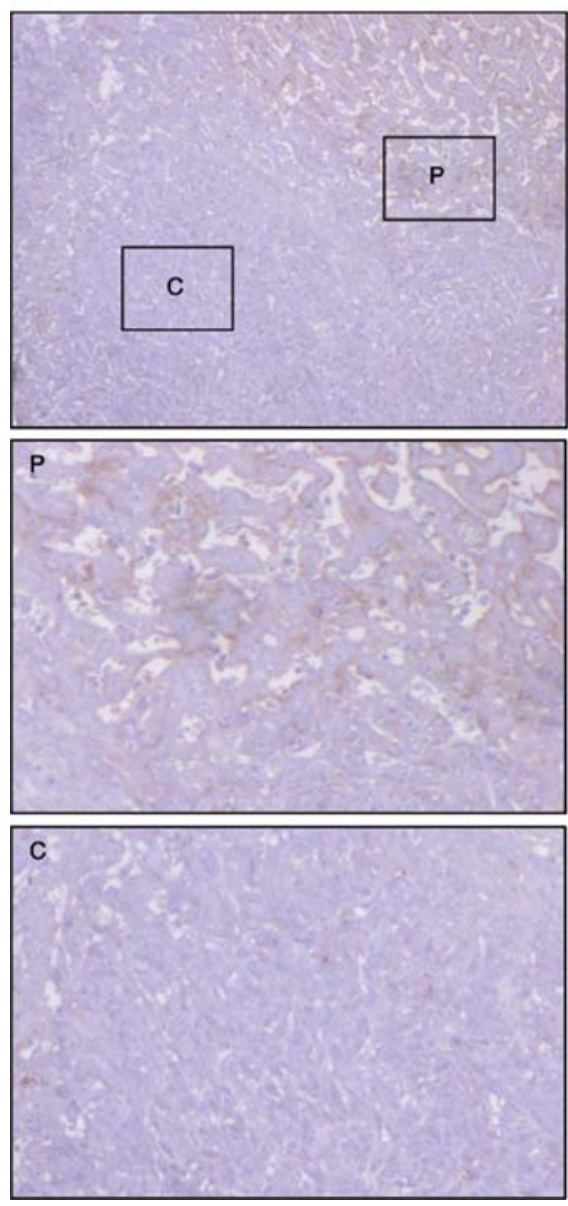

(B)

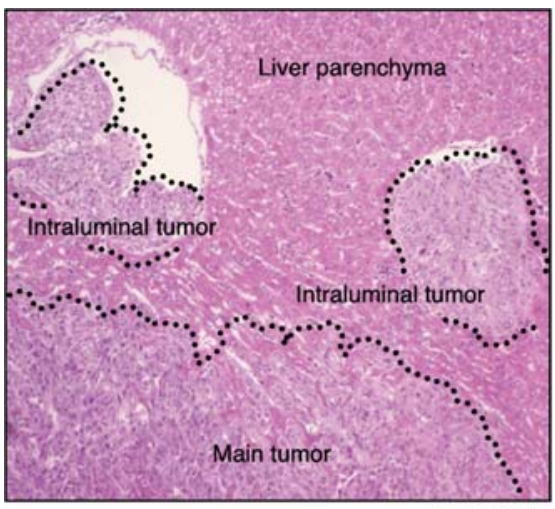

H.E. $\times 100$

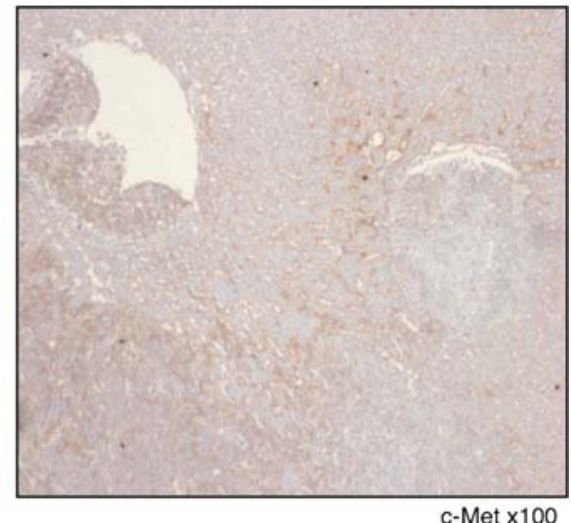

c-Met x100

Figure 8. The c-Met expression of murine liver metastatic sites was evaluated by an immunohistochemical study. (A) Immunohistochemical staining of liver metastatic tumor by c-Met. (a-c) Reduction of the c-Met expression is shown in the central area of the main tumor C. In contrast, the peripheral area; $\mathrm{P}$ has the invasive form and shown the c-Met expression clearly. (a: original magnification, $\mathrm{x} 100$; b: magnification of the P area, $\mathrm{x} 200$; c: magnification of the $\mathrm{C}$ area, $\mathrm{x} 200)$. (d-f) The peripheral area of main tumor $\mathrm{M}$ infiltrates around the tumor and has gland-formation that presents c-Met strongly. The satellite lesion $\mathrm{S}$ has irregular nest-formation in the vascular invasive components and occupies the space completely. That lesion dose not present c-Met. (d: original magnification, x100; e: magnification of the $\mathrm{M}$ area, x200; f: magnification of the $\mathrm{S}$ area, $\mathrm{x} 200$ ). (B) The peripheral area of the main tumor grew invasively and expressed c-Met and the tumor invaded the lumina (left side) expresses c-Met strongly. Another tumor also occupied the space of lumina (right side) completely, but did not express c-Met strongly.

study, because the wall depth of cancer invasion is a principal indicator for the progression of distant metastasis (26), first of all, the local situation was unified. Then, leading data indicated that high expression of c-Met in primary CRC site correlated with metastasis in the liver and lymph nodes. HGF-related c-Met pathway activation is critical for not only $\mathrm{CRC}$ progression, but also liver regeneration after hepatic resection. It has been feared that hepatectomy would induce 


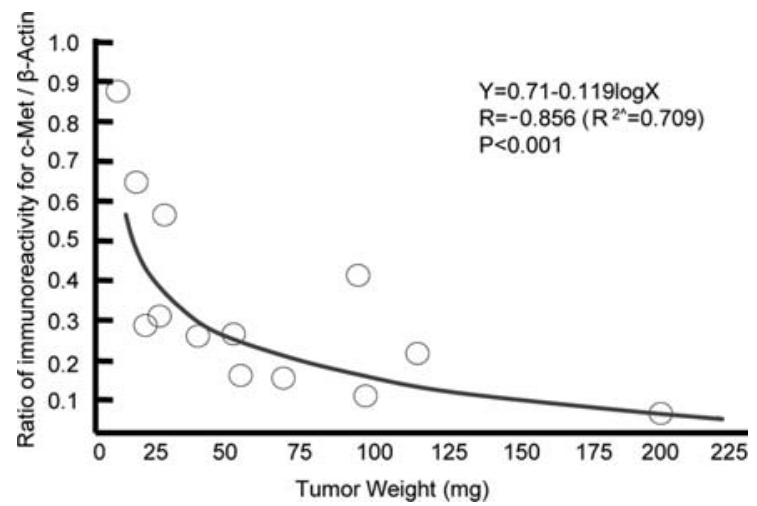

Figure 9. All tumors were collected from the same mouse and injected into the spleen with CT26 cells by day 28 . The c-Met expression of each whole tumor nodule was examined by Western blot analysis. Tumor weight and cMet expression were in good logarithmic correlation. $(\mathrm{p}<0.001,|\mathrm{R}|=0.856$, $\left.\mathrm{R}^{2}=0.709\right)$.

tumor growth of the residual liver (27-30), but no evidence for this has been demonstrated. Therefore, the present study was planned from the beginning to argue the advantages and disadvantages of surgical procedures for CRC liver metastasis. From immunohistochemical experiments on clinical specimens, the c-Met protein expression in liver metastatic tumors was found to decrease in comparison to the corresponding primary tumor. Western blot analysis also demonstrated the transition of c-Met expression in small number of selected cases, as shown in Fig. 2. The expression of c-Met is estimated to decrease in liver metastatic lesions, despite an elevated detection of this marker relating to the induction of liver metastasis. In contrast, a comparison of cMet expression in three synchronous liver metastasis cases showed no significant differences between primary and metastatic tumors (24). To clarify this phenomenon, basic experiments, both in vitro and in vivo, were carried out.

Receptor expression is regulated by the extracellular conditions, and repeated binding of ligands also mediates a trigger for the down-regulation of membrane-bound receptors $(31,32)$. Liver is usually believed to include high levels of HGF in its tissue, so there is a possibility that c-Met expression in the metastatic tumor is down-regulated. However, a high level of tissue HGF in liver has not yet been demonstrated, and the present study also showed a decrease of cMet in spleen tumor tissue. Therefore, this concept of c-Met down-regulation in liver metastatic tumors might not be supportable. Recently a novel concept for cancer growth and invasion has focused on the epithelial mesenchymal transition (EMT), in which cancer cells change their characteristics from local growth to an invasive and/or metastatic ability as part of their progression $(33,34)$. Generally speaking, EMT is well-recognized at the invasive front line of the cancer mass, but not in localized tumors (35). After moving to distant sites away from the primary tumor, the mesenchymal-epithelial transition (MET) was also associated with a change in activity towards building mass formation $(23,35,36)$. HGF itself is well-known as a scatter factor (SF) $(31,37)$, and is involved in the regulation of not only cell growth, but also cell motility and morphology (38). Carcinoma cells with HGF/SF have already demonstrated a relationship with the
EMT $(39,40)$, suggesting that primary CRC cells with highexpression of c-Met gained their motility due to $\mathrm{HGF} /$ receptor activation, which enables progression to blood vessels and/or distant organs. The present study shows that c-Met expression was reduced in a time- and tumor size-dependent manner after tumor formation at the metastasis site (Fig. 8). Taken together, the HGF/c-Met system mediates cancer growth in the steps from local expansion to arrival at a distant site, and is reduced during mass formation at secondary sites. In contrast to this, the level of c-Met mRNA expression was shown to increase in liver tumors when compared with culture conditions. To explain this phenomenon, the occurrence of post-translational modification, which controls the protein translation rate, the half-lives of specific proteins or mRNAs or intracellular location of the protein products (41), might be necessary. This theory explains that the level of mRNA expression does not always correlate with protein expression (9), and that the reducing c-Met protein is not induced by levels the expression of this mRNA. Further trials should be conducted to demonstrate this phenomenon.

HGF has been believed to be involved in proliferation for various types of cancers though the stimulation of c-Met (38). Although it is still unclear whether HGF has a universal cell proliferation role due to the observation of an inhibitory effect in some cell lines (42), the activation of a c-Met/ERKrelated cyclin-dependent pathway in this study indicated that HGF mediated the growth of the CT26 colorectal cancer cell line in culture. However, despite a 1.35-fold increase in serum HGF in $12 \mathrm{~h}$, hepatectomy was found to induce almost no visible effect on the growth of the remaining liver tumors. This observation supported the results for c-Met reducing in metastatic tumor tissue. Although there was no significant meaning in tumor size, after reduction of tumors by hepatectomy the remaining tumors were shown to decrease in size. The presence of cancer cell networks was also expected, and recently cancer cell-induced interleukin-6, CXCL-8 (interleukin-8) as a member of chemokine family or C-C chemokine motif ligand 2/5 were found to inhibit the drug-induced apoptosis and stimulate cancer cell proliferation (43). Thus, hepatectomy with some remaining tumors mediates not only reduction of tumor mass, but also blockage of the cancer growing network, related with these types of cytokines.

In conclusion, clinical features for CRC indicated that over-expression of c-Met was closely associated with liver and lymph node metastasis. This is a reason why metastasis occurred due to the HGF/SF-associated cell motility. On the other hand, in liver metastatic lesions, a reduction in the over-expressed c-Met was well correlated with a reduction in tumor growth. Therefore, even if serum HGF levels increased due to liver resection during the regeneration period, aggressive hepatectomy would still be acceptable and favorable as a curative therapy.

\section{References}

1. Kamangar F, Dores GM and Anderson WF: Patterns of cancer incidence, mortality, and prevalence across five continents: defining priorities to reduce cancer disparities in different geographic regions of the world. J Clin Oncol 24: 2137-2150, 2006.

2. Lochan R, White SA and Manas DM: Liver resection for colorectal liver metastasis. Surg Oncol 16: 33-45, 2007. 
3. Bengtsson G, Carlsson G, Hafstrom L and Jonsson PE: Natural history of patients with untreated liver metastases from colorectal cancer. Am J Surg 141: 586-589, 1981.

4. Bengmark $S$ and Hafström L: The natural history of primary and secondary malignant tumors of the liver. II. The prognosis for patients with hepatic metastases from gastric carcinoma verified by laparotomy and postmortem examination. Digestion 2: 179-186, 1969.

5. Park M, Dean M, Cooper CS, Schmidt M, O'Brien SJ, Blair DG and Vande Woude GF: Mechanism of met oncogene activation. Cell 45: 895-904, 1986.

6. Bottaro DP, Rubin JS, Faletto DL, Chan AM, Kmiecik TE, Vande Woude GF and Aaronson SA: Identification of the hepatocyte growth factor receptor as the c-Met proto-oncogene product. Science 251: 802-804, 1991.

7. Birchmeier C and Gherardi E: Developmental roles of HGF/SF and its receptor, the c-Met tyrosine kinase. Trends Cell Biol 8: 404-410, 1998

8. Di Renzo MF, Olivero M, Giacomini A, et al: Overexpression and amplification of the met/HGF receptor gene during the progression of colorectal cancer. Clin Cancer Res 1: 147-154, 1995.

9. Takeuchi H, Bilchik A, Saha S, et al: c-MET expression level in primary colon cancer: a predictor of tumor invasion and lymph node metastases. Clin Cancer Res 9: 1480-1488, 2003.

10. Michalopoulos GK and DeFrances MC: Liver regeneration. Science 276: 60-66, 1997.

11. Imai H, Saio M, Nonaka K, et al: Depletion of $\mathrm{CD} 4^{+} \mathrm{CD} 25^{+}$ regulatory $\mathrm{T}$ cells enhances interleukin-2-induced antitumor immunity in a mouse model of colon adenocarcinoma. Cancer Sci 98: 416-423, 2007.

12. Euhus DM, Hudd C, LaRegina MC and Johnson FE: Tumor measurement in the nude mouse. J Surg Oncol 31: 229-234, 1986.

13. Shimada $\mathrm{T}$, Mizutani $\mathrm{S}$, Muto $\mathrm{T}$, et al: Cloning and characterization of FGF23 as a causative factor of tumorinduced osteomalacia. Proc Natl Acad Sci USA 98: 6500-6505, 2001.

14. Osada S, Tomita H, Tanaka Y, Tokuyama Y, Tanaka H, Sakashita F and Takahashi T: The utility of vitamin K3 (menadione) against pancreatic cancer. Anticancer Res 28: 45-50, 2008

15. Osada S, Saji S and Kuno T: Clinical significance of combination study of apoptotic factors and proliferating cell nuclear antigen in estimating the prognosis of hepatocellular carcinoma. J Surg Oncol 85: 48-54, 2004.

16. Osada S, Saji S and Takahashi T: A case report of papilla Vater carcinoma showing positive expression of thymidine phosphorylase. Hepatogastroenterology 51: 375-377, 2004.

17. Osada S, Kanematsu M, Imai H, Goshima S and Sugiyama Y: Evaluation of extracellular signal regulated kinase expression and its relation to treatment of hepatocellular carcinoma. J Am Coll Surg 201: 405-411, 2005.

18. Glunde K, Raman V, Mori N and Bhujwalla ZM: RNA interference-mediated choline kinase suppression in breast cancer cells induces differentiation and reduces proliferation. Cancer Res 65: 11034-11043, 2005.

19. Tomita H, Yamada Y, Oyama T, et al: Development of gastric tumors in Apc(Min/+) mice by the activation of the betacatenin/Tcf signaling pathway. Cancer Res 67: 4079-4087, 2007.

20. Primrose JN: Treatment of colorectal metastases: surgery, cryotherapy, or radiofrequency ablation. Gut 50: 1-5, 2002

21. Choti MA, Sitzmann JV, Tiburi MF, et al: Trends in long-term survival following liver resection for hepatic colorectal metastases. Ann Surg 235: 759-766, 2002.

22. Nordlinger B, Vaillant JC, Guiguet M, Balladur P, Paris F, Bachellier P and Jaeck D: Survival benefit of repeat liver resections for recurrent colorectal metastases: 143 cases. Association Francaise de Chirurgie. J Clin Oncol 12: 1491-1496, 1994.

23. Stangl R, Altendorf-Hofmann A, Charnley RM and Scheele J: Factors influencing the natural history of colorectal liver metastases. Lancet 343: 1405-1410, 1994.
24. Fujita S and Sugano K: Expression of c-Met proto-oncogene in primary colorectal cancer and liver metastases. Jpn J Clin Oncol 27: 378-383, 1997.

25. Fazekas K, Csuka O, Köves I, Rásó E and Tímár J: Experimental and clinicopathologic studies on the function of the HGF receptor in human colon cancer metastasis. Clin Exp Metastasis 18: 639-649, 2000.

26. Wolmark N, Fisher ER, Wieand HS and Fisher B: The relationship of depth of penetration and tumor size to the number of positive nodes in Dukes C colorectal cancer. Cancer 53: 2707-2712, 1984.

27. de Jong KP, Lont HE, Bijma AM, et al: The effect of partial hepatectomy on tumor growth in rats: in vivo and in vitro studies. Hepatology 22: 1263-1272, 1995.

28. Harun N, Nikfarjam M, Muralidharan V and Christophi C: Liver regeneration stimulates tumor metastases. J Surg Res 138: 284-290, 2007

29. Rashidi B, An Z, Sun FX, Sasson A, Gamagammi R, Moossa AR and Hoffman RM: Minimal liver resection strongly stimulates the growth of human colon cancer in the liver of nude mice. Clin Exp Metastasis 17: 497-500, 1999

30. Ikeda Y, Matsumata T, Takenaka K, Sasaki O, Soejima K and Sugimachi K: Preliminary report of tumor metastasis during liver regeneration after hepatic resection in rats. Eur J Surg Oncol 21: 188-190, 1995.

31. Rubin C, Gur G and Yarden Y: Negative regulation of receptor tyrosine kinases: unexpected links to $\mathrm{c}-\mathrm{Cbl}$ and receptor ubiquitylation. Cell Res 15: 66-71, 2005.

32. Komada $M$ and Kitamura N: The Hrs/STAM complex in the downregulation of receptor tyrosine kinases. J Biochem 137: 1-8, 2005.

33. Hay ED: The mesenchymal cell, its role in the embryo, and the remarkable signaling mechanisms that create it. Dev Dyn 233: 706-720, 2005.

34. Lee JM, Dedhar S, Kalluri R and Thompson EW: The epithelial-mesenchymal transition: new insights in signaling, development, and disease. J Cell Biol 172: 973-981, 2006.

35. Brabletz T, Jung A, Reu S, et al: Variable beta-catenin expression in colorectal cancers indicates tumor progression driven by the tumor environment. Proc Natl Acad Sci USA 98: 10356-10361, 2001.

36. Vincan E and Barker N: The upstream components of the Wnt signalling pathway in the dynamic EMT and MET associated with colorectal cancer progression. Clin Exp Metastasis 25: 657-663, 2008.

37. Weidner KM, Arakaki N, Hartmann G, et al: Evidence for the identity of human scatter factor and human hepatocyte growth factor. Proc Natl Acad Sci USA 88: 7001-7005, 1991.

38. Jiang W, Hiscox S, Matsumoto K and Nakamura T: Hepatocyte growth factor/scatter factor, its molecular, cellular and clinical implications in cancer. Crit Rev Oncol Hematol 29: 209-248, 1999.

39. Elliott BE, Hung WL, Boag AH and Tuck AB: The role of hepatocyte growth factor (scatter factor) in epithelial-mesenchymal transition and breast cancer. Can J Physiol Pharmacol 80: 91-102, 2002.

40. Zhang A, Wang MH, Dong Z and Yang T: Prostaglandin E2 is a potent inhibitor of epithelial-to-mesenchymal transition: interaction with hepatocyte growth factor. Am J Physiol Renal Physiol 291: F1323-F1331, 2006.

41. Gygi SP, Rochon Y, Franza BR and Aebersold R: Correlation between protein and mRNA abundance in yeast. Mol Cell Biol 19: 1720-1730, 1999.

42. Jiang WG, Lloyds D, Puntis MC, Nakamura T and Hallett MB: Regulation of spreading and growth of colon cancer cells by hepatocyte growth factor. Clin Exp Metastasis 11: 235-242, 1993.

43. Levina V, Su Y, Nolen B, et al: Chemotherapeutic drugs and human tumor cells cytokine network. Int J Cancer 123: 2031-2040, 2008. 